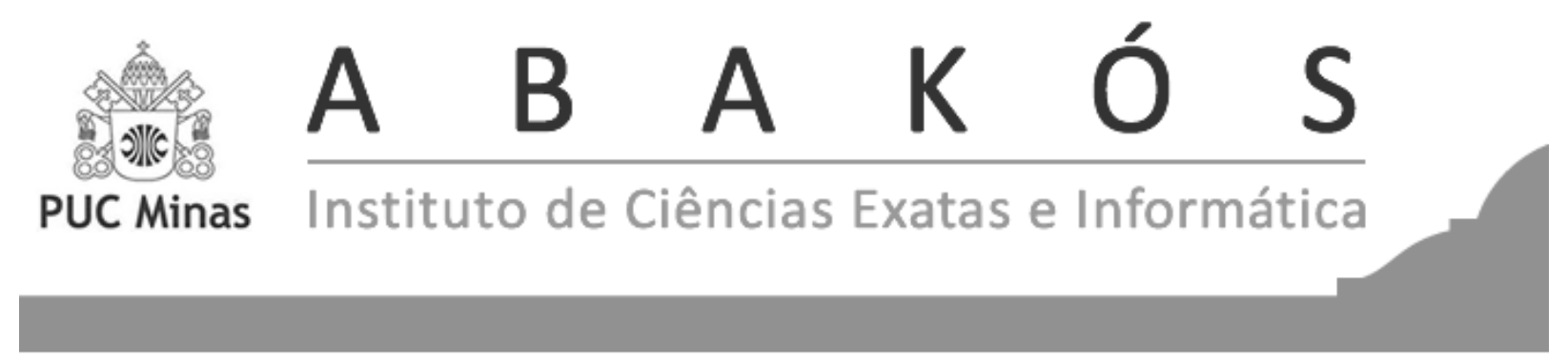

\title{
COGNIC - A Mobile Device Application Used for Cognitive Stimulation in Older People with Dementia*
}

COGNIC - Um Aplicativo para Dispositivo Móvel Usado na Estimulação Cognitiva de Idosos com Demência

\section{Antônio Augusto de Faria Guimarães Melo Pertence ${ }^{1}$ \\ Rosilane Ribeiro da Mota ${ }^{2}$ \\ Luciana de Oliveira Assis ${ }^{3}$}

\begin{abstract}
Resumo
A demência é uma doença mental prevalente entre idosos e é caracterizada por déficit cognitivo acentuado. A doença de Alzheimer é a demência mais frequente e afeta a memória e outras funções cognitivas dos indivíduos. Ainda não há cura para a doença, porém, existem tratamentos que podem aliviar os sintomas cognitivos e controlar os comportamentos dos pacientes. O uso de aplicativos para smartphones e tablets para o tratamento nãofarmacológico das demências, em geral, vem aumentando progressivamente nos últimos anos. Este artigo apresenta o desenvolvimento de um aplicativo para dispositivos móveis com base na plataforma $A n d r o i d \AA$, a partir de diretrizes estabelecidas na literatura, a ser utilizado com acompanhamento de profissionais de saúde, durante o atendimento de idosos com diagnósticos de demência leve a moderada devido ao Alzheimer. Foram feitos testes de usabilidade e aplicados questionários, sendo que os resultados da avaliação indicaram que o aplicativo atendeu aos objetivos propostos, validando as diretrizes estabelecidas para o seu desenvolvimento a partir da literatura.
\end{abstract}

Palavras-chave: Doença de Alzheimer. Demência. Estimulação cognitiva. Aplicativo. Dispositivo móvel.

\footnotetext{
* Submetido em 24/09/2019 - aceito em 04/03/2021.

${ }^{1}$ Mestre em Ciência da Computação do Programa de Pós-Graduação em Informática da PUC Minas, Brasil- antonio.pertence@sga.pucminas.br

${ }^{2}$ Professora do Curso de Ciência da Computação da PUC Minas, Brasil-rosilane@ pucminas.br

${ }^{3}$ Professora Adjunta do Departamento de Terapia Ocupacional da Universidade Federal de Minas Gerais, Brasillassis@ufmg.br
} 


\begin{abstract}
Dementia is characterized by marked cognitive impairment and is a prevalent mental illness among older people. Alzheimer's disease is the most frequent form of dementia, affecting memory and other cognitive functions. Although there is no cure for the disease, there are treatments that can relieve cognitive symptoms and control the behavior of affected individuals. In recent years, there has been a progressive increase in the use of applications designed for smartphones and tablets for the non-pharmacological treatment of dementia. This article describes the development of an application for mobile devices with the Android ${ }^{\circledR}$ platform operating system based on guidelines established in the literature to be used by health professionals who provide care for older people with a diagnosis of mild to moderate dementia due to Alzheimer's disease. The application was evaluated employing usability tests and questionnaires, the results of which indicated that the application met the proposed objectives, validating the guidelines established in the literature for the development of applications for this population.
\end{abstract}

Keywords: Alzheimer's disease. Dementia. Cognitive stimulation. Application. Mobile devices. 


\section{INTRODUCTION}

The increase in life expectancy around the world offers the opportunity for people to enjoy a longer life. However, this situation is accompanied by an increase in the prevalence of diseases related to the aging process, including dementia. According to the most recent Diagnostic and Statistical Manual of Mental Disorders (DSM) issued by the American Psychiatry Association in 2013, dementia is a major neurocognitive disorder characterized by marked cognitive deficit due to the neurodegenerative process in older people. This process can affect attention, processing speed, memory, orientation, reasoning, concentration, learning, the accomplishment of complex tasks, judgment, language, and visuospatial skills (DSM-5, 2013) (PESSOA et al., 2016).

Alzheimer's disease is the most common form of dementia and is characterized as a degenerative disease that initially affects memory, followed by other cognitive functions. The progressive decline exerts a negative impact on the performance of activities of daily living as well as social and occupational aspects (ALZHEIMER, 2019).

Alzheimer's disease has three stages of evolution: initial or mild; intermediate or moderate; and final or advanced. In the first stage, which can last from two to four years, the patient begins to experience memory problems that affect the ability to perform activities of daily living. The second stage can last from two to ten years, during which the individual begins to experience dysfunctions in terms of reasoning, emotions, and behavior, becoming progressively dependent on others. In the third and last phase, the individual is wholly dependent on others; reasoning and communication capacities deteriorate very quickly until he/she is no longer able to communicate or even move, becoming bedridden (ALZHEIMER, 2019). Although there is no cure, pharmacological and non-pharmacological interventions can delay the progress of the disease, alleviate cognitive symptoms and control the behavior of affected individuals (DE MARCHI et al., 2015)

This paper describes the development of an application for mobile devices with the Android ${ }^{\circledR}$ platform operating system based on guidelines established in the literature to be used by health professionals who provide care for older people with a diagnosis of mild to moderate dementia due to Alzheimer's disease. The application was evaluated employing usability tests and questionnaires administered to patients and healthcare providers. The experience of patients using the smartphone represents a positive side effect for the application of the test.

\section{LITERATURE REVIEW}

Among non-pharmacological treatments, cognitive stimulation has been used as a function-oriented support strategy designed to enable individuals with mild to moderate dementia remain significantly involved in their lives and contexts. As global and specific cognitive functions are interrelated with important functional aspects that enable participation in everyday 
life, recent efforts have been made to develop structured, function-oriented, person-centered approaches to cognitive stimulation that can be tailored to the needs of an individual or group (YUILL; HOLLIS, 2011). In this respect, there has been a progressive increase in the use of games and activities offered through applications for smartphones and tablets to improve cognitive function in individuals with dementia, such as GreyMatters (GREYMATTERS, 2019), MindMate (MINDMATE, 2019), Next-Number (NEXT-NUMBER, 2019), and MemoTouch (MEMOTOUCH, 2019).

GreyMatters was developed for tablets on the iOS $®$ platform and is based on the idea of an interactive life storybook, the aim of which is to improve the quality of life of individuals with dementia and their caregivers. Through visual reminiscence paired with music and games, the app helps patients and families preserve memories and share meaningful experiences (GREYMATTERS, 2019). The application enables creating a personalized user life history book by adding moments that are part of the patient's long-term memories, thus promoting communication between individuals with dementia and the people around them. The app also enables recording and sharing current experiences, capturing special moments that occur during the use of the app, and sharing them with family members. Historical facts can be recalled by accessing content of interest to the patient, such as artists, movies, and pop culture from past decades. One can also create an audiovisual reminder with photographs, texts, and voice narration that can reassure the patient, helping him/her avoid embarrassment and contain anxiety. This application can be used in the home environment as well as in an institutional or clinical setting.

The MindMate application developed for Android ${ }^{\circledR}$ and iOS $®$ platforms offers interactive games to stimulate the patient's cognitive skills and help with memory problems. This app also offers advice on the practice of physical exercises and adequate nutrition to help older people live a healthier life and remain active, thereby preserving physical and mental fitness (MINDMATE, 2019). The patient can store memories and construct their life story, which can be shared with family and friends. They can store all their personal information, such as favorite foods and music. It is also possible to watch movies on the app as well as listen and dance to musical successes from past decades.

The Next-Number application on the iOS $®$ platform for use in smartphones was developed for the rehabilitation and stimulation of cognitive functions to improve concentration, the speed of actions, and visual memory. It has similarities with the cognitive evaluation denominated "Trails", but is not proposed as a cognitive evaluation system or the evaluation of attention or speed. It has different levels of difficulty to be chosen for the game, with or without time restriction to finish the proposed challenge (NEXT-NUMBER, 2019).

The MemoTouch application was developed for the Android® and iOS $®$ platforms and functions as a reminder of dates, appointments, events, details of the daily routine, etc. It also has links to phones and e-mails (family, doctors, therapists, etc.) and other information to assist in caring for older people. The application helps reduce confusion in older people who cannot remember what they should do and what is going on in their world, helping them manage the 
details of daily living and feel in control again. For caregivers, the app can reduce the intensity of interactions with older people, reducing the stress caused by the patient follow-up process. Family members, healthcare providers, and neighbors can follow the patient at a distance, keeping informed and taking part in the care of older people, enabling the adequate coordination of efforts on the part of all people involved in the older people's life (MEMOTOUCH, 2019).

Robert et al. (2014) report that the benefits of games in the treatment, stimulation, and rehabilitation of patients with dementia are not yet fully understood, as clinical, ethical, economic, and research aspects have not been systematically addressed in target populations. Thus, it is necessary to establish guidelines to improve the effectiveness of these applications in a multidisciplinary collaboration process involving developers, researchers, clinicians, healthcare providers, patients, caregivers, family members, and even mobile device manufacturers as well as national and international health agencies through communication and the exchange of information.

Moreover, there is a need to develop applications that have an interface in Portuguese as the default language, as the applications listed above were developed in English and do not enable translation into other languages, which limits their use in Brazil (PESTILI; BETTI, 2015).

\section{METHODS}

For the development of the application, guidelines were established from the literature and information obtained with health professionals aiming at the creation of the interface and the best usability. The interface and usability guidelines were used as a reference to establish the functional and non-functional requirements of the application.

\subsection{Established Guidelines}

The guidelines established in the literature for an application of this type include simplicity in the presentation of the information, ease of interaction (not requiring attention to numerous details) (SILVA FILHO, 2007), and the use of large icons and letters. It is preferable to use non-serifed fonts to facilitate the reading of the letters on the screen (NIELSEN; LORANGER, 2007; LABIUTIL, 2019). The composition of the application should have color combinations that contribute to the stimulation of cognitive function (CESAR, 2019), while seeking to avoid excessive brightness and low contrast (PERRACINI, 2006).

Larger images without much detail should be used, as problems with spatial relationships occur with the evolution of dementia, which may hinder the understanding of the application (MA, 2019). Touch commands (basically a click) are preferable, as this facilitates interactions with the application, giving the user a greater sense of control (SILVA FILHO, 
2007).

Scrollbars are not advisable. All information should be displayed at once on the screen, preferably vertically, to make it easier to view and navigate through the application (MA, 2019). A responsive design should be used, enabling the application to adapt to the screen size of each mobile device and maintaining the content organized (KNIGHT, 2019). Table 1 indicates the established guidelines for the development of applications for older people with dementia.

\section{Table 1 - Guidelines for development of applications for older people with dementia}

\begin{tabular}{|c|}
\hline Simplicity of organization and ease of interaction \\
\hline Large icons, letters, and images \\
\hline Non-serifed fonts \\
\hline Color sets that avoid excessive brightness and low contrast \\
\hline Touch commands \\
\hline Do not use scroll bars \\
\hline Responsive design \\
\hline
\end{tabular}

Source: Authors.

\subsection{Usability Testing}

Usability testing was performed for the evaluation of the application. This process involved a team of three occupational who daily provided care for older people with dementia. The therapists were given a commercially available smartphone with a five-inch screen on which the application had been installed.

Eight usability tests were performed with patients ranging from 71 to 88 years of age (four men and four women) at a single time. One occupational therapist performed two tests with the patients and the other two occupational therapists each performed three tests with the patients. All patients were in outpatient care, had a diagnosis of mild to moderate Alzheimer's disease, and had experience with using a smartphone.

The therapists were instructed on the use of the device and were asked to employ the application in their clinical practice. The device was available at the clinic for 20 days. Questionnaires were also given to the therapists so that they could evaluate the application with regards to the following metrics: understanding the functioning of the application, the ease of instructing patients on the effectiveness of the application, and navigation errors. The following metrics related to the patients were also evaluated: understanding the use of the application through interaction with the different interface objects; understanding the instructions given by the therapist regarding the use of the application; and the difficulty in completing tasks.

Each item on the questionnaire was scored on a Likert scale (LIKERT, 1932) with five response options: two positive evaluations, one neutral, and two negative evaluations (quantitative aspect). The therapists were also asked to list their impressions (positive and negative) of the technology, offer suggestions and comments, and record their patients' impressions (qua- 
litative aspect) (CAVALCANTI, 2019). No evaluation was performed of the effectiveness of the application for the treatment of dementia in these patients, since the device was used for a short period during the usual treatment of cognitive stimulation that the patients were already receiving (NOBRE et al., 2003).

This work received approval from the institutional review board of Universidade Federal de Minas Gerais (certificate number: 08506418.0.0000.5149). Figure 1 schematically illustrates the method used for the development of the application.

Figure 1 - Method used for application development

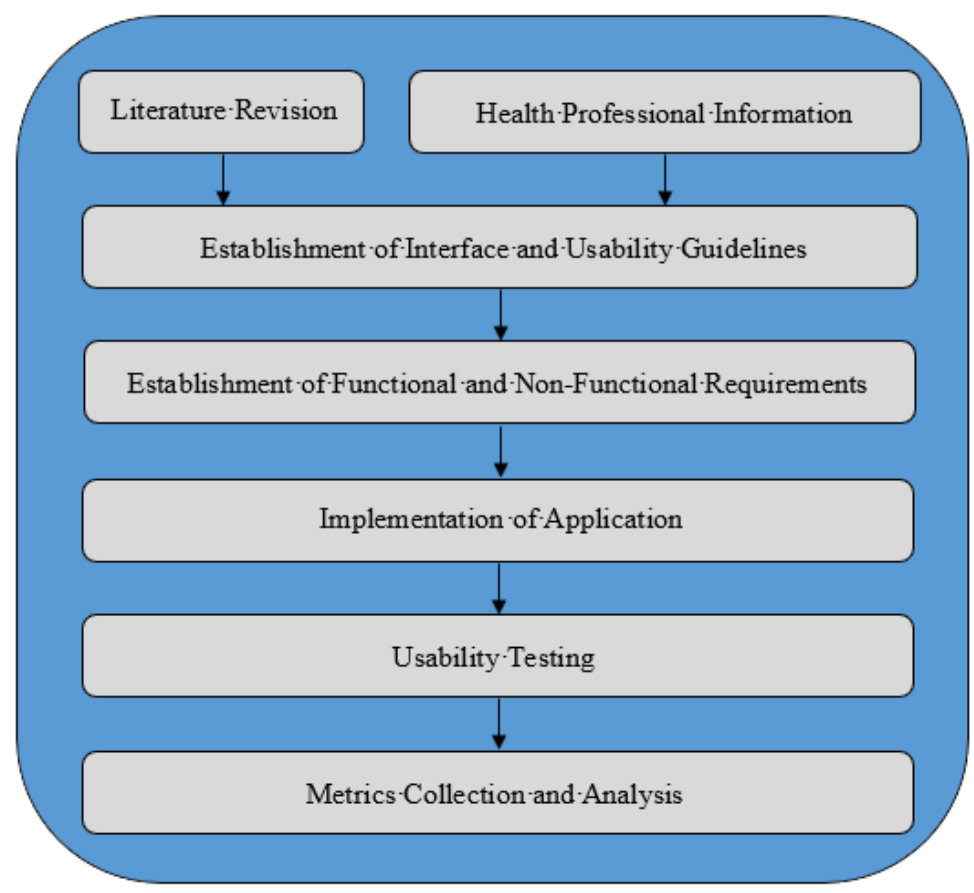

Source: Authors.

\subsection{Implementation of Application}

Android ${ }^{\circledR}$ Studio (ANDROID STUDIO, 2019) was used for the project because it is the official integrated development environment (IDE) for mobile application development with the Android operating system. This IDE was developed by Google with support from JetBrains ${ }^{\circledR}$. The interface was written in XML (Extensible Markup Language), which is a markup language. The program was written in Java ${ }^{\circledR} 7$, officially supported language by the Android platform (JAVA, 2017), using the Android ${ }^{\circledR}$ libraries (source code and resource files). These technologies are also officially supported by Google. The application requires a device running Android ${ }^{\circledR}$ version 4.4 or above and at least 2 gigabytes of RAM to run. 


\section{RESULTS}

\subsection{Non-Functional Requirements}

The application was developed for mobile devices using the Android® platform considering the therapeutic protocol of cognitive stimulation. The theme was an activity of daily living (grocery shopping) involving work with quantities (payment of purchases) and the relationship between elements (products purchased and places to store these products in the home). Figures (images in the public domain) and visual stimuli (characteristic elements that indicate whether the user performed the task correctly) were used with follow-up by a healthcare provider on an individual basis and on only one level of difficulty (PREGNOLATO, 2019; MEEN, 2019).

The application sought to provide an interface more adapted to the patient with the provision of the instructions as on a sheet of paper from the adoption of logic that follows the idea of the "pencil and paper" format, that is, the tasks or situations appear in a sequence of screens where the instructions are presented from top to bottom (MENDOZA; GOLINO, 2016). Portuguese was used as the default language in its interface, to facilitate its use by patients in Brazil (PESTILI; BETTI, 2015).

\subsection{Functional Requirements}

Figure 2 shows the 'Initial' and 'Supermarket Activity' screens on which the user respectively starts using the application and is invited to perform an activity of daily living corresponding to grocery shopping.

Figure 3 shows the 'Shopping List' screen, on which the user must memorize a randomly established shopping list. On the 'Products' screen (Figure 3), the user must choose the products from the list by touching the appropriate products shown on the screen. Each hit prompts a green color indicator next to the image, along with the word "Correct". Each error prompts a red color indicator next to the image and the word "Incorrect". The user is encouraged to try other options, with the green and red color indicators remaining alongside the previously chosen images. The number of errors committed until all the hits are achieved is used as the basis for indicating the degree of difficulty faced by the user. 
Figure 2 - Initial and Supermarket Activity screens

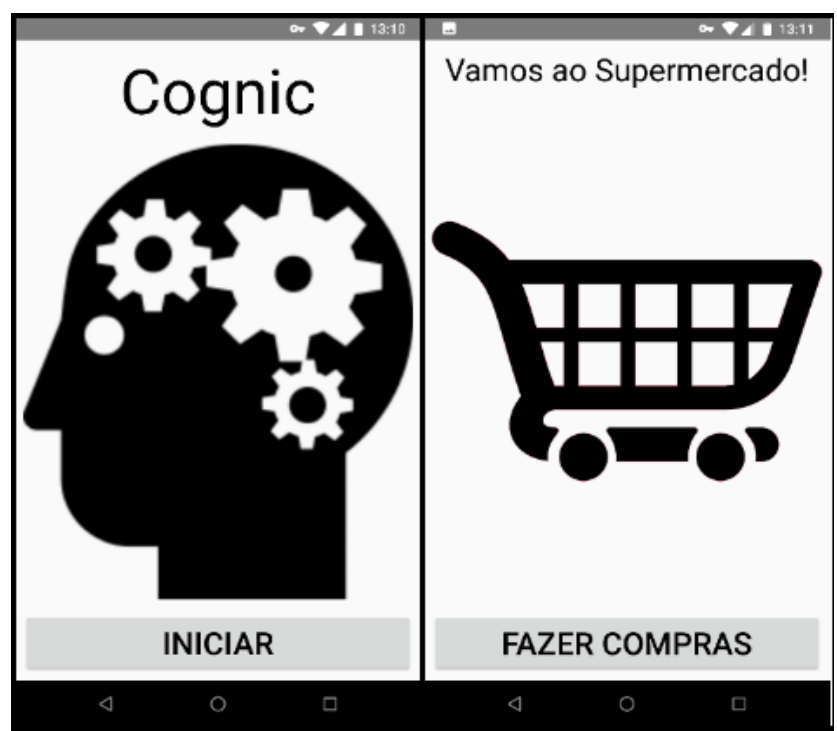

Source: Authors.

Figure 3 - Shopping List and Products screens

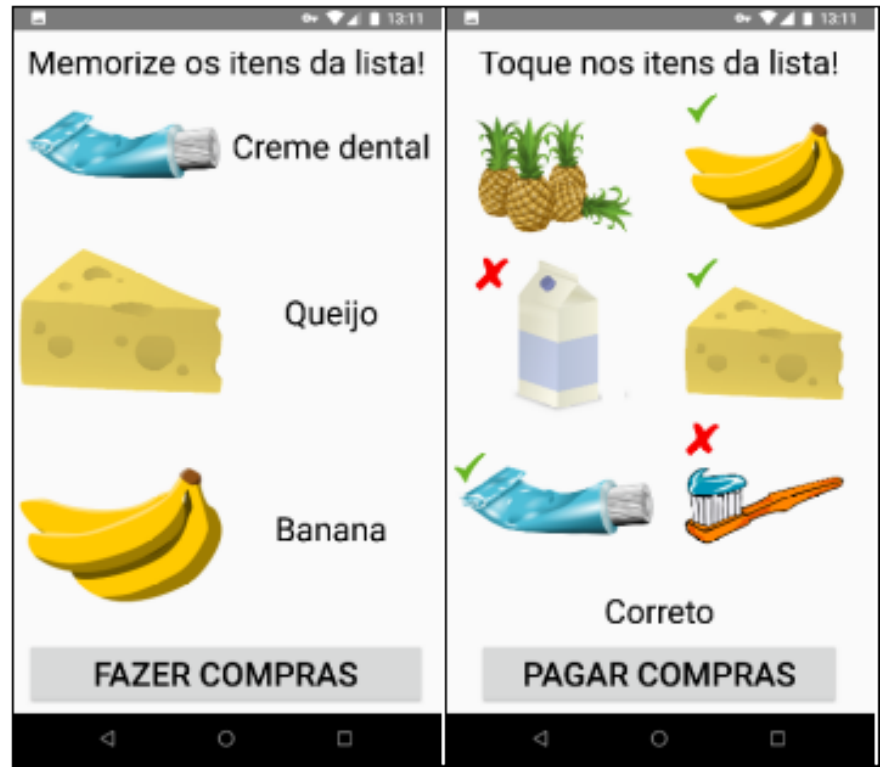

Source: Authors.

On the 'Pay for Purchases' screen, the user makes payments based on the value established for each product. Integer values are used to facilitate working with quantities, as indicated in Figure 4. As coins and notes are selected, the corresponding values are added to the amount paid, which is compared to the total amount payable. If the amount paid surpasses the total amount payable, the user must restart the process. 
Figure 4 - Payment Purchases screen

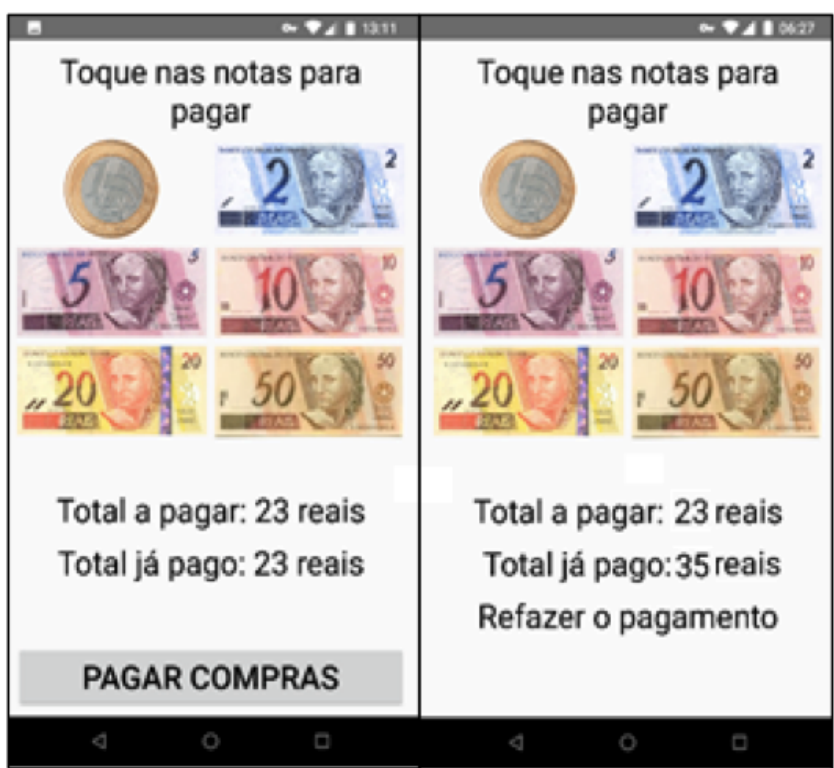

Source: Authors.

The user can select the option to perform a new shopping activity, exit the application, or choose to store the items purchased in their respective places in the home, as indicated on the 'Home Activity' screen. To do so, the user must consider a list of places displayed on the 'Places to Store Purchases' screen, as shown in Figure 5.

\section{Figure 5 - Home Activity and Places to Store Purchases screens}

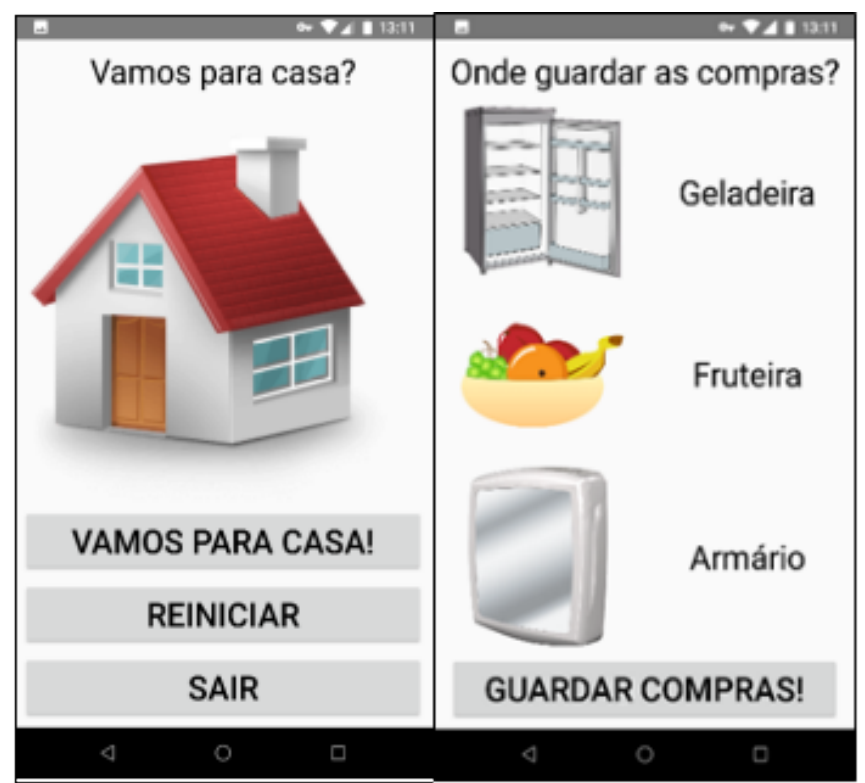

Source: Authors.

On the 'Store Purchases' screen, the products purchased are displayed one at a time. When a product is stored in the correct place, its image disappears. Otherwise, the word "Incorrect"appears, as shown in Figure 6. The user must try another location to store the product until choosing the correct place. At the end of this process, the user can start a new shopping activity or exit the application (Figure 6). Figure 7 shows the state machine diagram. 
Figure 6 - Store Purchases and Exit screens

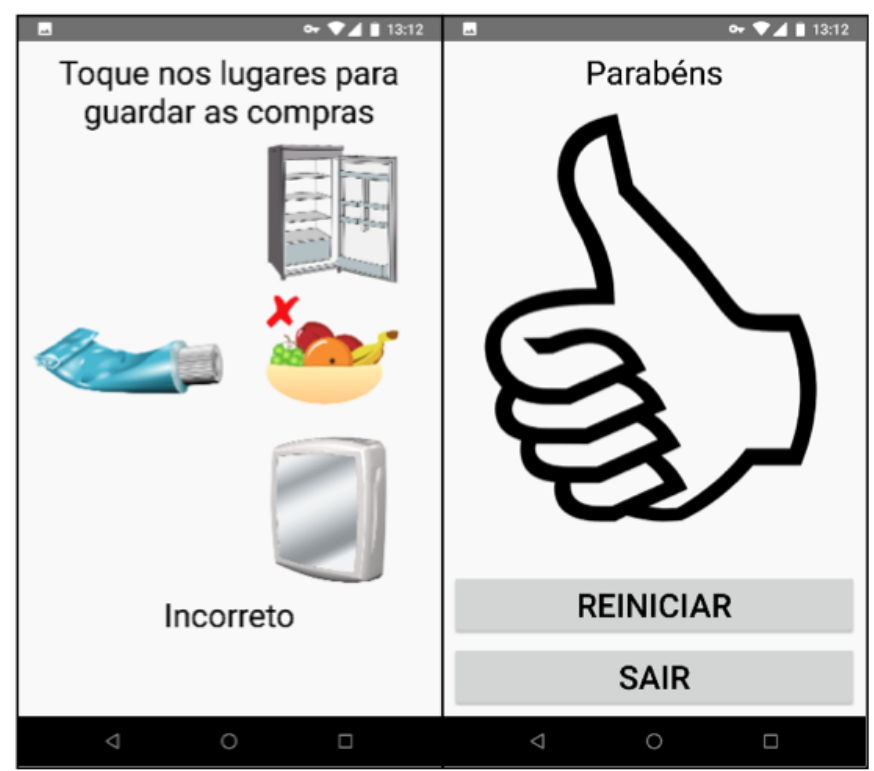

Source: Authors.

\subsection{Application Testing Results}

Figure 8 illustrates the results of the metrics addressed in the questionnaire regarding the understanding of the functioning of the application by the occupational therapists (metric A) and the ease of instructing patients considering the effectiveness of the use of the application and navigation errors (metric $\mathrm{B}$ ).

For metric A, two therapists considered the operation of the application very easy and one considered it easy. For metric B (ease of instructing patients on the effectiveness of the use of the application and navigation errors), two professionals rated it good and one rated it very good.

Figure 9 shows the results of the metrics related to the understanding of application use through interaction with the different interface objects (metric C); understanding or not of the instructions previously explained by the health professional (metric D); and the difficulty in completing tasks for the patient's case (metric E). 
Figure 7 - State machine diagram

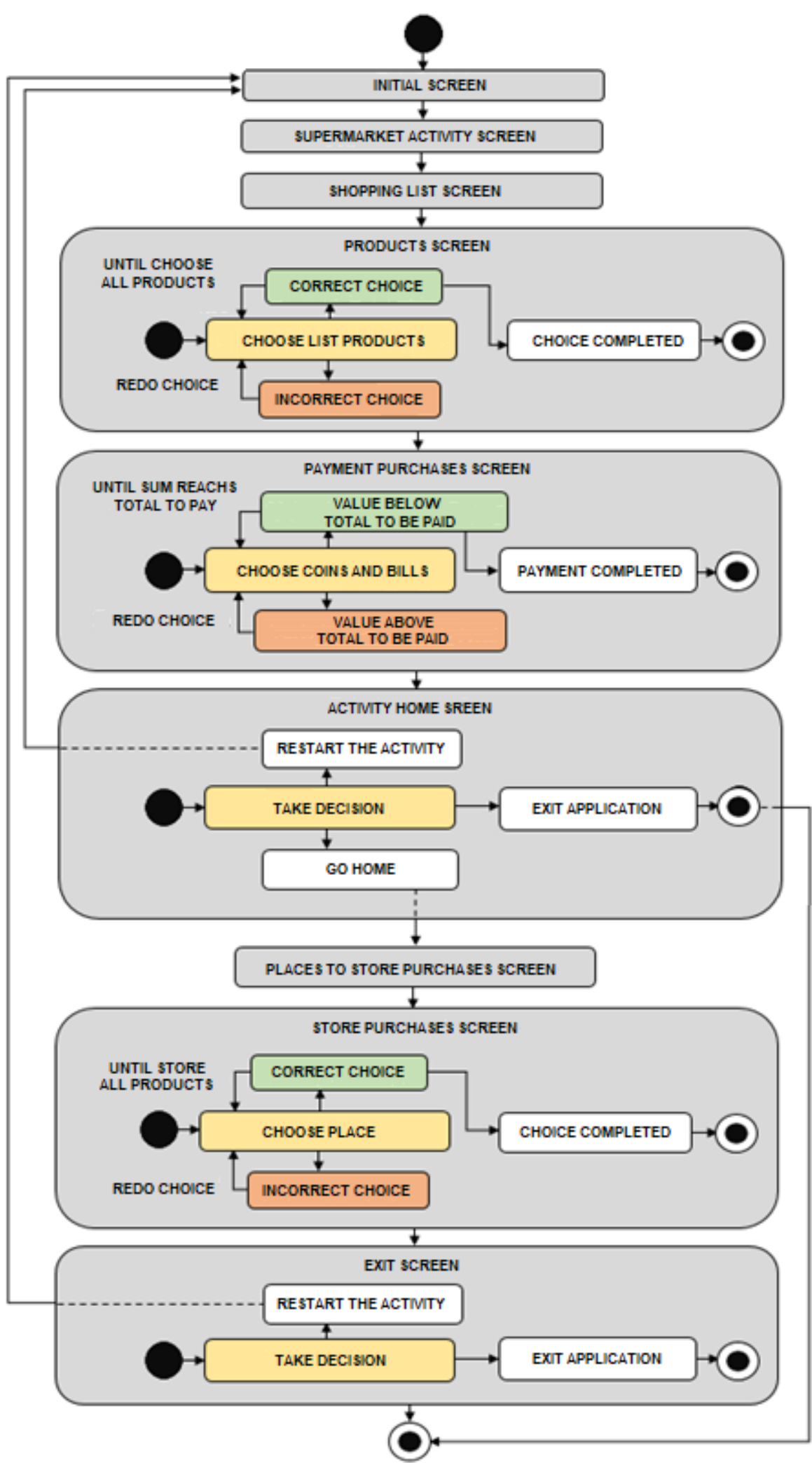

Source: Authors. 
Figure 8 - Metrics related to evaluation of Occupational Therapists

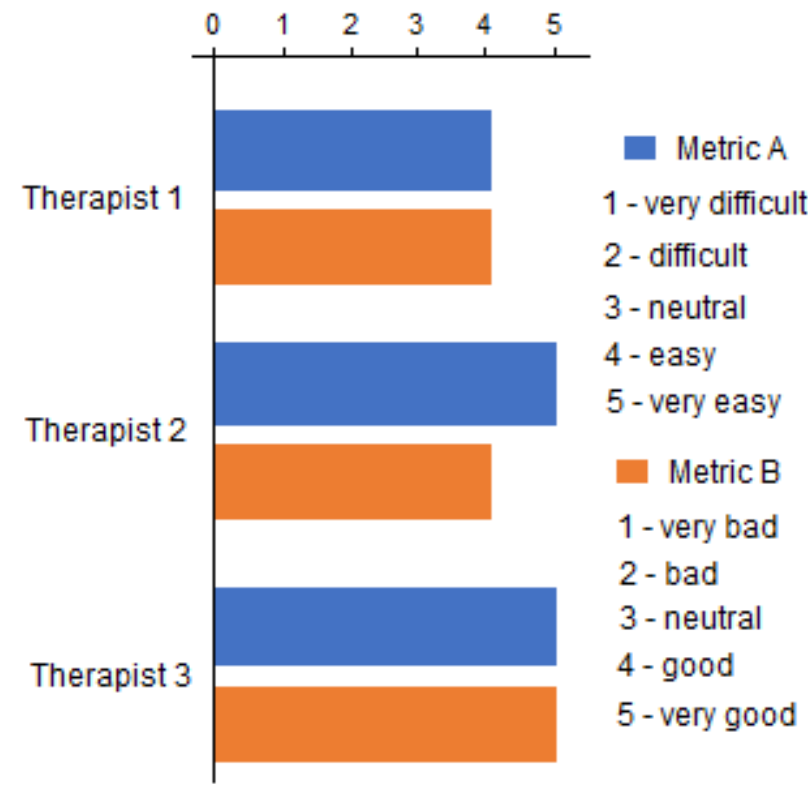

Source: Authors.

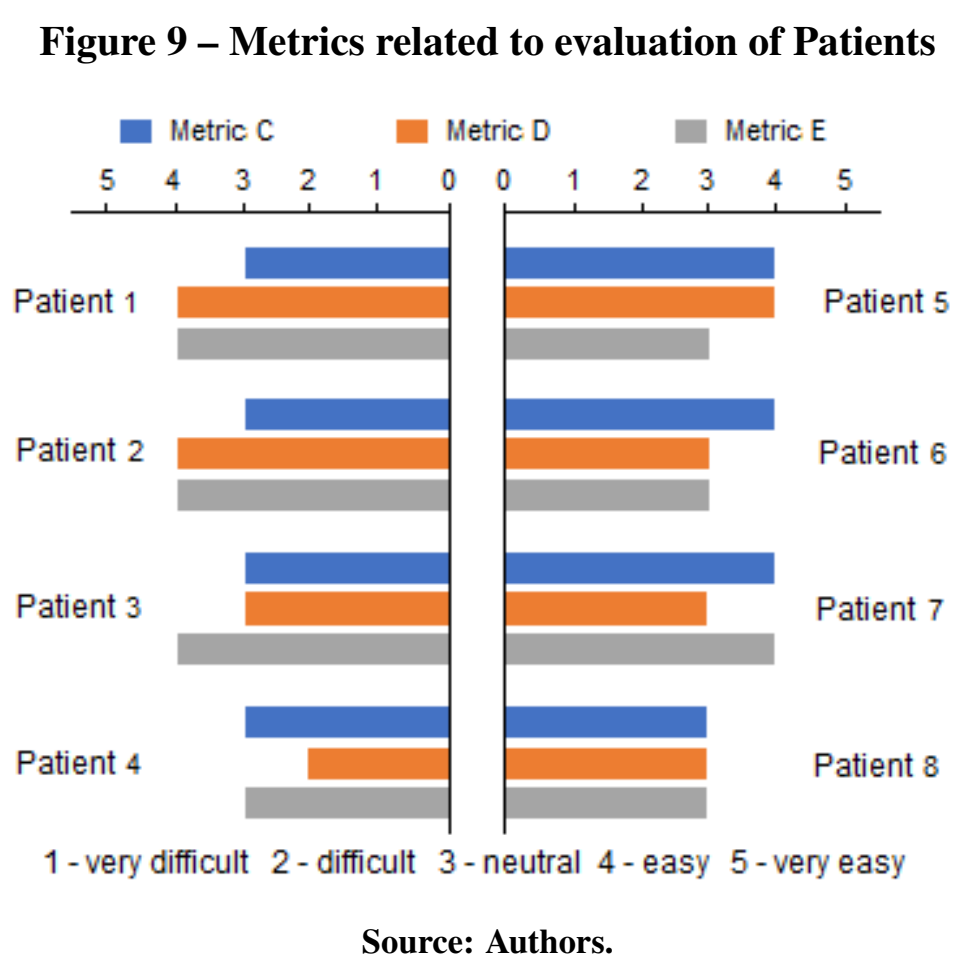

For metric $\mathrm{C}$ (interactions with the different interface objects), $62 \%$ of patients rated the application reasonable and 38\% rated it easy. For metric D (understanding of the instructions explained by the health professional), $50 \%$ of the patients rated it reasonable, $38 \%$ rated it easy and $12 \%$ rated it difficult. For metric E (difficulty in completing tasks), $50 \%$ of the patients rated it reasonable and $50 \%$ rated it easy.

As positive points of the application, the occupational therapists listed the fact that the theme used (shopping for groceries) is a common activity performed by individuals, but its use in the application was considered a novelty by the participating older people. This facilitated 
the acceptance of the application and stimulated it for use in general. The therapists also stated that the application presents images that are easily identifiable and the activity involves simple commands. The therapists stated that the application addresses attention, semantic and episodic memory, and aspects of executive function, such as categorization, logical reasoning, and calculation. As a negative point, the therapists indicated the need to use the application with the monitoring of an occupational therapist due to the patient's learning difficulty as a result of his/her health condition as well as difficulty in using the technology itself due to a low level of schooling in some cases or difficulty handling a smartphone. The occupational therapists suggested that the application could be developed further, expanding its scope of activities of daily living and the offering more levels of difficulty. They suggested improvements in the figures in terms of their recognition and scale. For example, the refrigerator and medicine cabinet are easily recognized, but should be presented more in scale, meaning that the refrigerator should appear larger than the medicine cabinet. They also suggested that the steps could be more flexible. For example, once the selection phase of the products on the shopping list has been completed, it would be possible to go directly to the home and move on to the storage phase without necessarily having to carry out the stage of paying for the purchases. This would make the application more adaptable to the condition of each patient. The occupational therapists also stated that the application would be more useful for patients in the early stage of dementia with good cognitive reserve, for whom the stimuli would have more positive responses. They also thought that the application would have greater acceptance among older people who have an interest in current affairs, news, and new experiences. In the collecting the impressions about the application made by occupational therapists, the patients indicated that they were generally interested and even surprised by the proposed activity due to its theme (purchases). They showed a willingness to learn and use the application and said that they enjoyed doing the activity. Some reported difficulty in storing the products from the shopping list, indicating that, while they recognized the products and places to store them, their home differs from that in the application. They also demonstrated difficulties with the technology itself and the touch screen interface. 


\section{CONCLUSION}

The results of the usability testing and the considerations offered by the occupational therapists and patients revealed that the application had an overall positive evaluation. Thus, the application reached its objective of being useful for older people with mild to moderate dementia and validated the guidelines established in the literature for the development of applications for this population. Compared to other applications cited in the literature review, the application developed in this study also enables cognitive stimulation through a simulated activity of daily living with a universal nature but should be used with the accompaniment of a healthcare provider on an individual basis. It offers a patient-adapted interface with instructions displayed in the "pencil and paper"format (presented from top to bottom as on a sheet of paper). The application also has an academic aspect and can be included in research protocols related to public health. For future versions, the application could be developed further, expanding its scope of activities of daily living and adding more levels of difficulty by increasing the number of items to be purchased, stored, or saved. The application could be made more adaptable to the condition of each patient through greater flexibility in choosing the order of execution of the phases. Finally, learning strategies should be developed to assist patients regarding how to use the application and handle smartphones in order to enable more autonomous use of the application without the need for the monitoring of an occupational therapist, at least in cases of milder dementia. 


\section{REFERENCES}

ALZHEIMER. Alzheimer's Disease International (ADI). 2019. Available from: <https: //www.alzint.org/about>. Accessed on 06/08/2019.

ANDROID STUDIO. O IDE Oficial do A ndroid. 2019. Available f rom: < https://developer. android.com/studio/index.html?hl=pt-br>. Accessed on 06/08/2019.

CAVAlCANTI, J. P. P. S. A Usabilidade de Aplicativos Móveis por Usuários Idosos: Estudo Baseado no Sistema Operacional iOs. 2019. Dissertação (Mestrado em CURSO) - Programa de Pós-Graduação em Design do Departamento de Artes Design da PUC-Rio. Available at: <https://www.maxwell.vrac.pucrio.br/Busca_etds.php? strSecao=resultado\&nrnrSeq=30066@ 1>. Accessed on 06/09/2019.

CESAR, E. O significado das cores e seus efeitos nas pessoas. 2019. Available from: <http: //www.espacodecorado.com/2009/04/o-significado-das-cores-e-seusefeitos-nas-pessoas $>$. Accessed on 17/09/2019.

DE MARCHI, A. C. B.; BIDUSKI, D.; CARON, J. Alz memory - um aplicativo móvel para treino de memória em pacientes com alzheimer. RECIIS - Rev. Eletron. Comum. Inf. Inov. Saúde, v. 9, n. 2, 2015.

DSM-5, AMERICAN PSYCHIATRIC ASSOCIATION. Diagnostic and Statistical Manual of Mental Disorders - DSM. Washington: D/C, 2013.

GREYMATTERS. Reaching Beyond Dementia. 2019. Available from: <https://www. grey-matterstous.com>. Accessed on 06/09/2019.

JAVA. Java SE 7u79 and 7u80. 2017. Available from: <http://www.oracle.com/technetwork/ pt/java/javase/downloads/jre7-downloads-1880261.html>. Accessed on 06/08/2019.

KNIGHT, K. Responsive design: What it is and how to use it. Smashing Magazine, 2019. Available from: <http://www.coding.smashingmagazine.com/2011/01/12/ guidelines-forres-ponsive-web-design>. Accessed on 17/09/2019.

LABIUTIL. Checklist para Avaliação de Acessibilidade da Web para Usuários Idosos. 2019. Available from:<http://www.labiutil.inf.uf-sc.br/acessibilidade/index.htm>. Accessed on 17/09/2019.

LIKERT, R. A technique for the measurement of attitudes. Archives of Psychology, p. 1-55, 1932.

MA, S. 10 Ways Mobile Sites Are Different from Desktop WebSites. 2019. Available from <http://www.uxmatters.com/mt/archives/2011/03/10-waysmobile-sites-are-different-from-desktop-websites.php>. Accessed on 17/09/2019.

MEEN. Mini Exame do Estado Mental. 2019. Available from: <https://pt.wikipedia.org/wiki/ Mini_exame_do_estado_mental>. Accessed on 06/09/2019.

MEMOTOUCH. Memo: Constant Reminders to Keep Daily Life on Track. 2019. Available from: <http://www.memotouch.com/>. Accessed on 06/09/2019.

MENDOZA, C. E. F.; GOLINO, M. T. S. Development of a cognitive training program for the elderly. Revista Brasileira de Geriatria e Gerontologia, v. 19, n. 5, 2016. 
MINDMATE. Makes a Difference Every Day. 2019. Available from: <www.mindmate-app. com>. Accessed on 06/09/2019.

NEXT-NUMBER. Train Your Brain. 2019. Available from: <http://vitotechnology.com/ next-numbers.html>. Accessed on 06/09/2019.

NIELSEN, J.; LORANGER, H. Usabilidade na Web: Projetando Websites com Qualidade. Rio de Janeiro: Elsevier, 2007.

NOBRE, M. et al. A prática clínica baseada em evidências. parte i - questões clínicas bem construídas. Revista da Associação Médica Brasileira, v. 49, n. 4, p. 445, 2003.

PERRACINI, M. R. Planejamento e adaptação do ambiente para pessoas idosas. In: FREITAS, E.V. et al. (Ed.). Tratado de Geriatria e Gerontologia. Rio de Janeiro: Guanabara Koogan, 2006. p. 1142-41.

PESSOA, R. M. P. et al. Da demência ao transtorno neurocognitivo maior: Aspectos atuais. Revista Ciências em Saúde, v. 6, n. 4, 2016.

PESTILI, L. C.; BETTI, N. F. S. Remember - aplicativo para o auxílio de idosos com alzheimer. In: CONFERÊNCIA DE ESTUDO EM ENGENHARIA ELÉTRICA, 13., 2015, Uberlândia. Anais [... ]. Uberlândia: Universidade Federal de Uberlândia (UFU), 2015.

PREGNOLATO, M. Estimulação Cognitiva para Adultos e Idosos. 2019. Available from: $<$ http://mariuzapregnolato.com.br>. Accessed on 06/09/2019.

ROBERT, P. H. et al. Recommendations for the use of serious games in people with alzheimer's disease, related disorders and frailty. Front Aging Neuroscience, v. 6, p. 54, 2014.

SILVA FILHO, A. M. S. Design de interfaces para idosos. Revista Espaço Acadêmico, v. 77, outubro 2007. Ano VII.

YUILL, N.; HOLLIS, V. A systematic review of cognitive stimulation therapy for older adults with mild to moderate dementia: An occupational therapy perspective. Occupational Therapy International, v. 18, p. 163-186, december 2011. Issue 4. 